See discussions, stats, and author profiles for this publication at: https://www.researchgate.net/publication/345431064

\title{
Toward a new paradigm of environmentally friendly cultural values
}

Preprint $\cdot$ November 2020

DOI: 10.13140/RG.2.2.18229.09447

CITATIONS

READS

256

9 authors, including:

Q. Quy Khuc

Vietnam National University, Hanoi

117 PUBLICATIONS 929 CITATIONS

SEE PROFILE

Minh-Hoang Nguyen

Phenikaa University

380 PUBLICATIONS 1,771 CITATIONS

SEE PROFILE

Some of the authors of this publication are also working on these related projects:

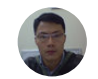

Tung Ho

Vietnam Academy of Social Sciences

224 PUBLICATIONS 1,809 CITATIONS

SEE PROFILE

Toan Manh Ho

Phenikaa University

107 PUBLICATIONS 908 CITATIONS

SEE PROFILE

Project Education and soft skills View project

Project $\quad$ Science Publishing View project 


\title{
Toward a new paradigm of environmentally friendly cultural values
}

Quy Van Khuc ${ }^{\text {a }}$, Manh-Tung $\mathrm{Ho}^{\mathrm{b}, \mathrm{c}}$, Hong Kong T. Nguyen ${ }^{\mathrm{c}}$, Minh-Hoang Nguyen ${ }^{\mathrm{c}}$, Manh-Toan $\mathrm{Ho}^{\mathrm{c}}$, Thu-Trang Vuong ${ }^{\mathrm{d}}$, Viet-Phuong $\mathrm{La}^{\mathrm{c}}$, Quan-Hoang Vuong ${ }^{\mathrm{e}}$

${ }^{a}$ Faculty of Economics and Business, Phenikaa University, Hanoi 100803, Vietnam

${ }^{\mathrm{b}}$ Ritsumeikan Asia Pacific University, Graduate School of Asia Pacific Studies, Beppu City, Oita Prefecture, 874-8577, Japan

${ }^{\mathrm{c}}$ Centre for Interdisciplinary Social Research, Phenikaa University, Hanoi 100803, Vietnam

${ }^{\mathrm{d}}$ Sciences Po Paris Campus de Dijon, 21000, Dijon, France

${ }^{\mathrm{e}}$ Centre Emile Bernheim, Université Libre de Bruxelles, B-1050 Brussels, Belgium

*Corresponding author. Email: quy.khucvan@ phenikaa-uni.edu.vn. Address: Room 305, Building A2, Phenikaa University, Ha Dong district, Hanoi, Vietnam.

Preprint DOI: https://osf.io/3g26q

Date: November 7, 2020

\begin{abstract}
Climate change gives rise to a growing threat of extinction to humankind, yet the current approach and solutions appear insufficient in addressing it effectively. This paper presents a critical review of the climate crisis and current approaches, highlighting how misguided would it be to exclude enterprises - the primary drivers of the climate problems - from top-down policy-making. In assessing the different core cultural values of environment-damaging and environment-protecting enterprises, the authors suggest embracing a new paradigm of environmentally-friendly cultural values. The new paradigm, which calls for a process of identifying, transforming, and synthesizing a set of core cultural values, serves as the cornerstone of the whole system and aims to shift the core cultural value from "exploitation" to "construction." As environmentally-friendly cultural values can shape human progress away from capitalism/monetarism and toward environmentalism, it could be added to Harrison and Huntington's (2001) list of human cultures as the $11^{\text {th }}$ value. The paradigm comprises two mutually interacting attributes: (i) money cannot
\end{abstract}


trade for environmental deficits, and (ii) environmental embellishment value needs to become a new "measure of profit," priced at least on par with monetary value. The insights carry serious implications for policy-makers in engaging enterprises in the fight for a more habitable and sustainable planet.

Keywords: Global environmental change, climate change, environmental value, cultural value, enterprises, semiconducting principle, mindsponge

"I only feel angry when I see waste. When I see people throwing away things we could use"

-Mother Teresa (1910-1997), A Gift for God, 1975

\section{The climate crisis: rethinking approaches}

Climate change is, doubtless, one of the biggest challenges facing humanity today and in the next decades or so. A steady stream of research is published every year documenting the imminent threats posed by climate change, from the rising sea level (Kulp \& Strauss, 2019), the declining global crop yields (Plagányi, 2019; Ray et al., 2019), to widespread forest disturbances (Seidl et al., 2017), losses in biodiversity (Barnosky et al., 2011; Johnson et al., 2017), and even increased psychological anxiety (Clayton, 2020), to name a few. No places on Earth are spared, but low-income countries are bearing the brunt of such impacts, with their economic outputs expected to suffer more (Nunn et al., 2019). For instance, the livelihood of more than 20 million inhabitants in the south of Vietnam, nearly a quarter of the Southeast Asian country's population, is in imminent danger as the land there could be submerged underwater at high tide by 2050 , according to a research study published by Nature Communications (Kulp \& Strauss, 2019). In fact, heavy rainfall, floods, and inundation are already happening not just across Vietnam but also elsewhere on a daily, monthly, and yearly basis. At a global scale, the Economist Intelligence 
Unit's (EIU) Climate Change Resilience Index estimates that direct economic costs from climate change might hit USD7.9 trillion by 2050, or a 3\% fall in global GDP (Galey, 2019).

While these facts may seem indisputable, the responses to climate adaption have not met with the same unanimous acceptance. To put the situation into context, recall the Pigouvian tax, introduced by the British economist Arthur C. Pigou in 1920, which sets out to charge any market transactions that generate a negative externality borne by individuals without any direct involvement in the transactions. Nearly a century has passed since Pigou's ideas were discussed and the carbon tax imposed, but there is yet a universally accepted action plan to address the climate crisis. While all United Nations member states in 2015 adopted the Sustainable Development Goals (SDGs), which include alleviating the impacts of climate change (United Nations, 2015), the goals have been criticized for being too wide-ranging, cumbersome, and difficult to be implemented and monitored (Bali Swain, 2017; Hickel, 2015). Then, in 2017 U.S. President Donald Trump withdrew the world's largest economy from the Paris climate accord, COP21, under which nearly 200 countries have pledged to reduce greenhouse emissions (White House, 2017). The high-level decision-making in this regard has been inconsistent, to say the least.

In order to improve policy-making in the mitigation and adaption to climate change, it is necessary to refresh our mindset and reshape our approaches. Even though climate change is partly to blame, continuous human exploitations over the years have compounded the ecological loss and degradation. Within the current picture, production activities at the enterprise level, fueled by the ever-constant business as a usual mindset, play a primary role in exacerbating environmental pollution. On this premise, this study makes the case that enterprises should not be cast out of climate policy-making. In breaking down the different core cultural values of environmentdamaging and environment-protecting enterprises, the study suggests embracing a new paradigm 
of environmental cultural values to shift the core cultural value from "exploitation" to "construction."

\section{Bad enterprises, good enterprises}

Given the complexity in quantifying the damages of climate change and the polluters' role, there is no consensus yet on assigning climate responsibilities. The "Common but Differentiated Responsibilities and Respective Capabilities" principle under the United Nations Framework Convention on Climate Change outlines that industrialized nations that produced the largest share of historic greenhouse gas emissions must bear more responsibility (United Nations, 1992). However, scholars have pointed out other ways to attribute responsibilities, one of which requires paying more attention to societal actors such as fossil fuel companies, industry trade associations, and lobbying groups (Frumhoff, Heede, \& Oreskes, 2015; Heede, 2014). Thus, it is without dispute that enterprise-induced production activities are major drivers of global carbon emissions and environmental pollution (Davies, Hernandez, \& Wyatt, 2019; Ekwurzel et al., 2017; Frumhoff et al., 2015; Griffin, 2017).

Identifying the primary causes aside, one cannot leave out the actions taken to mitigate the problem. Among the responses to date, the carbon emissions trade and the carbon tax-based approach are the most well-known, though carbon trading is met with mixed evaluations. On the one hand, some researchers have noted an appropriate carbon tax level can push enterprises toward pursuing long-term emission reduction (Kuo, Hong, \& Lin, 2016). On the other hand, other researchers have noted that the mechanism has exacerbated the issue instead (Lapan \& Sikdar, 2019; Rosen, 2015; Rosenbloom, Markard, Geels, \& Fuenfschilling, 2020; van den Bergh \& Botzen, 2020). In this context, is carbon emissions trade insufficient to help reduce the global $\mathrm{CO}_{2}$ emissions, or is this a legal excuse for enterprises to increase exploitation and further polluting the 
environment? According to estimates from the U.S. Department of Energy, global $\mathrm{CO}_{2}$ emissions caused by enterprises have jumped by almost 90\% since 1970 (Boden, Marland, \& Andres, 2017). Figure 1 recaptures the dramatic hike in annual $\mathrm{CO}_{2}$ emissions between 1970 and 2018 due to the burning of fossil fuels for energy and cement production.

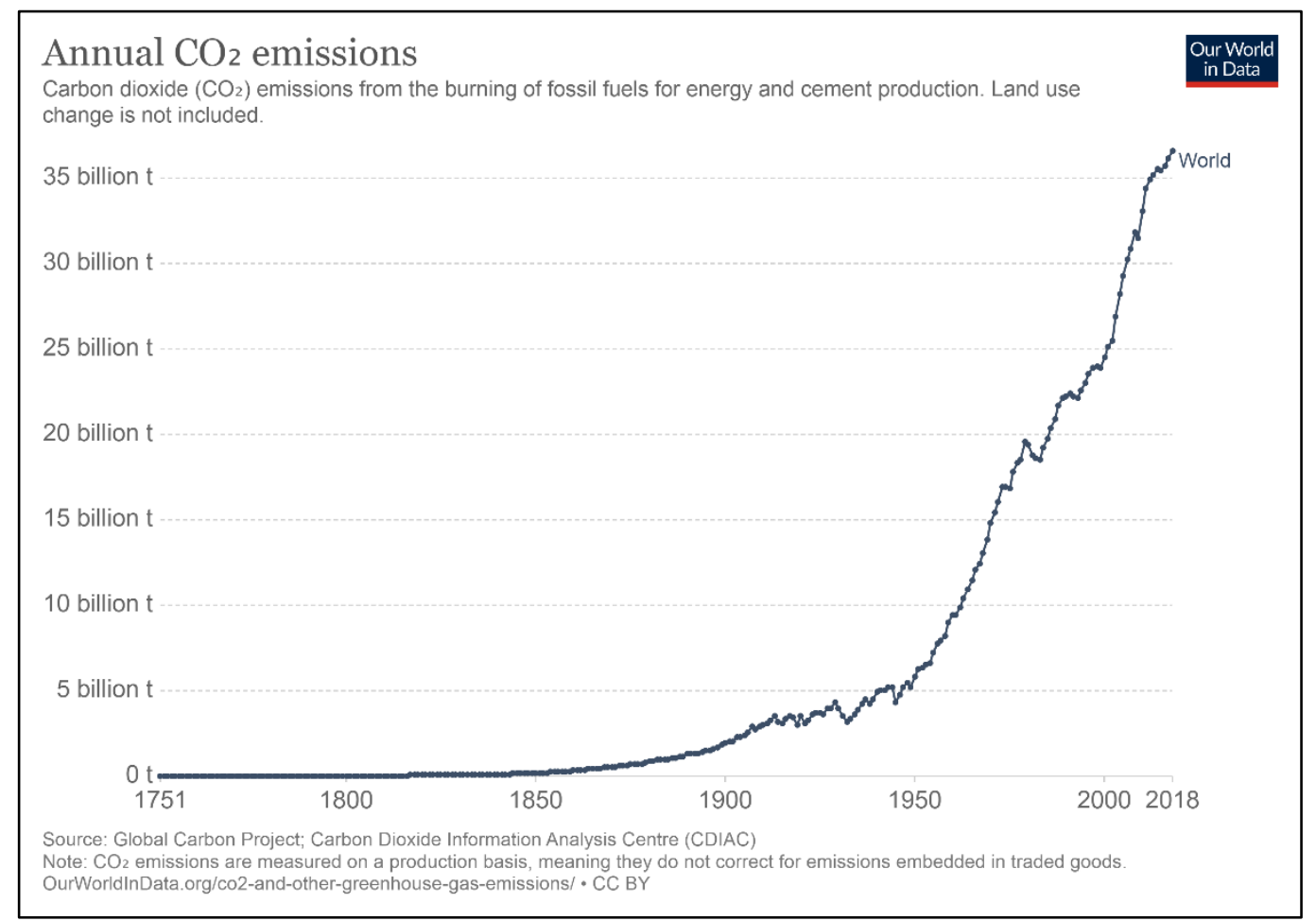

Figure 1. Growth in global carbon emission. Source: www.ourworldindata.org

Heavy-polluting enterprises are clearly the industrial carbon producers for they consume high-carbon energy, such as coal and petroleum, and are yet to innovate their technologies toward large-scale energy conservation. Some recent studies on heavy industrial enterprises have focused on exposing energy consumption and carbon dioxide emissions by Chinese firms, such as in the steel industry (Price et al., 2002), the nonferrous metals industry (Yanjia \& Chandler, 2010), or the coal chemical industry (Zhang et al., 2019), etc. Enterprises that take actions deemed as bad for the environment and the indigenous communities, however, can also take the guise of 
environmentally-conscious companies or have associations with an international body. For instance, the Vietnamese conglomerate Hoang Anh Gia Lai Group, which was once linked to the financial arm of the World Bank, the International Finance Corporation (IFC), owns several rubber plantations in Cambodia but has been repeatedly accused of taking away indigenous lands and destroying forests in Cambodia since 2014 by international watchdogs and Cambodian organizations (IDI, 2020; Peter \& Pheap, 2014). A different study on Vietnamese enterprises' engagement in environmental initiatives has notably found that, between 2012 and 2019, the number of environment-damaging events is larger than that of environmental protecting events (Vuong et al., 2020). Worse still, many enterprises that belong to the environmental protection industry, such as forestry, have been caught in the negative chain of events (Vuong et al., 2020).

As enterprises have become such big drivers of global environmental change, underestimating their role in solving the problem could be a terrible mistake. On the bright side, some environmental protection activities and or initiatives with the responsible participation of enterprises have been implemented in many parts of the world. For example, in the U.S., the electric car company Tesla, one of the most climate-conscious automakers in the world, has been ranked at the top of the list thanks to zero carbon emissions from its products (McMahon, 2018; Rimmer, 2018). The American outdoor apparel company Patagonia is making clothes with organic cotton, hemp, and recycled nylon and polyester, intending to reduce adverse impacts on the environment. In Sweden, the world's largest furniture retailer, IKEA, has committed to "climate positive" by 2030, and in February 2020 reported its climate footprint fall for the first time (IKEA, 2020; Reuters, 2020).

Meanwhile, the International Union for Conservation of Nature (IUCN) Vietnam has launched the Vietnam Business for Environment (VB4E) initiatives (www.vb4e.com $)$ to run many 
projects engaging enterprises to reduce plastic waste and protect the environment. These projects cover various environmental protection fields including plastic waste, forest restoration, education, sustainable tourism, renewable energy, biodiversity, and coastal and island protection. Overall, enterprises with a climate-conscious pursuit across continents have taken various actions, such as implementing green supply chain management, nature-based tourism, social entrepreneurship, etc., contributing to the development of circular economies.

The involvement of enterprises in reducing environmental pollution and mitigating climate change could increase the odds of success for several reasons. First, they can afford to partially alter policies. Second, they hold a considerable volume of resources or capital. Third, they have a strong mechanism to seek and operate solutions effectively. Finally, they have more strong economic incentives and social responsibility to thrive in an increasingly competitive world (Vuong et al., 2020).

\section{Environmentally-friendly cultural values: a new paradigm}

This paper proposes a new paradigm in addressing the climate crisis. This section delves into the details of what is meant by environmentally-friendly cultural values, particularly the processes of identifying, transforming, and synthesizing a set of core cultural values.

\section{Identification}

The idea of a core cultural value or belief is not new and has been subject to numerous research (Harrison \& Huntington, 2001; Mor, Toma, Schweinsberg, \& Ames, 2019). In order to shift our approach to climate problems, it is necessary to grasp how our core cultural values are formed. A set of core values can be the cornerstone of an individual or organization. In this context, as the enterprises are the main subject, the set of core cultural values, whether they be profiteering 
or sustainable in essence, acts as the foundation of the enterprises. Here, we suggest visualizing the core values in a logical diagram (Figure 2), as Vuong (2020) lays out.

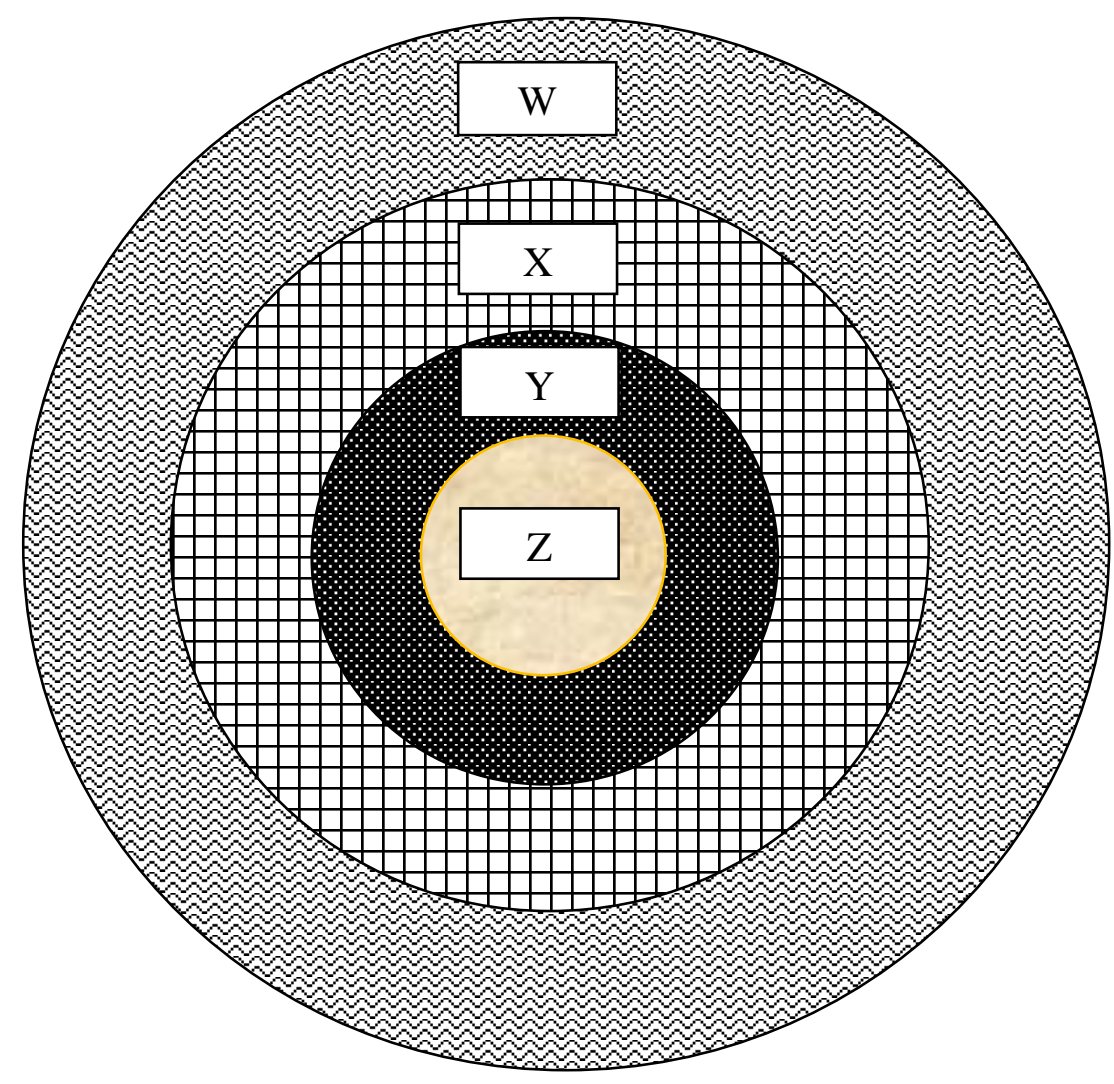

Figure 2. The logic of solving climate change problems based on a cultural value system

According to Vuong (2020), Figure 2 is explained as follows.

W: The very existence of humankind requires social sciences in tackling global problems (Shah, 2020).

$\mathrm{X}$ : Climate change problems constitute one of the most critical subsets of the most dangerous global problems (Victor, 2015). Therefore, solving climate change problems will need to embed social sciences in its system of equations. 
Y: As part of the social sciences, cultural research plays a crucial role in mediating society's responses to serious climate problems (Straughan \& Dixon, 2012). This gives rise to our critically important question on cultural values of adaptation to climate change and environmental sustainability (Adger, Barnett, Brown, Marshall, \& O’brien, 2013).

Z: According to the modus operandi of mindsponge processes, society needs to form a consensus in establishing key cultural values, which emerge to serve the task of finding efficient cultural responses to the climate change and sustainability threats, as required by $\mathrm{Y}$, and hence, the whole system from $\mathrm{W}$ to $\mathrm{Y}$. Here is the catch: The system of core progressive values stated and widely adopted by Lawrence E. Harrison failed to provide a nature-protecting (or healing) cultural element (Harrison, 2000). In fact, this seminal work barely mentioned today's most essential keywords, such as "environment" or "nature" or "sustainability."

As Vuong (2020) surmises, if set $\mathrm{Z}$ is empty $(Z=\emptyset)$, then there is a real problem of a missing core cultural value in dealing with the climate crisis. In other words, if a whole system of climate response is built on a set of zero elements, it is bound to fail. Perhaps one of the main reasons why there is an increasingly louder voice, in both academia and policy-making circles, about the likely failure to deliver the promise of those SDGs dealing with the environmental problems.

The above problem with lack of a core cultural value reflects the unanswered ontological question: who will likely serve as the determining force in finding solutions to the environmental problems and then implementing them? It is the business sector that necessarily has to engage in the quest for sustainability solutions, not just for the businesses themselves but also for humankind at large. 


\section{Transformation}

How does the transformation of core cultural values take place in the business sector? The scholarship on enterprises and climate change reveals that sustainability initiatives largely fall under the ubiquitous corporate social responsibility (CSR) framework. Yet, it would be a mistake for enterprises to address climate problems solely through the CSR lens because that approach does not get to the heart of the corporate-driven problem. Similarly, it would be gravely misguided to portray enterprises in a negative light, casting them out of the climate mitigation and adaptation policy-making. As such, although enterprises taking on social responsibility is important and inevitable, entrepreneurs and policy-makers alike should think about a more strategic response to the problems rather than a purely temporal and philanthropic one. In this sense, it is crucial to understand what distinguishes environment-damaging enterprises from environment-protecting ones? This study suggests the answer lies in this new paradigm encompassing environmentallyfriendly cultural values. Given the growing demand for saving the environment, enterprises must change their core cultural value from "exploitation" to "construction" (Figure 3). The transition in corporate cultural values is a prerequisite for changing corporate behavior in environment protection practices since cultural values can shape human progress (Harrison \& Huntington, 2001; Waas, 2014).

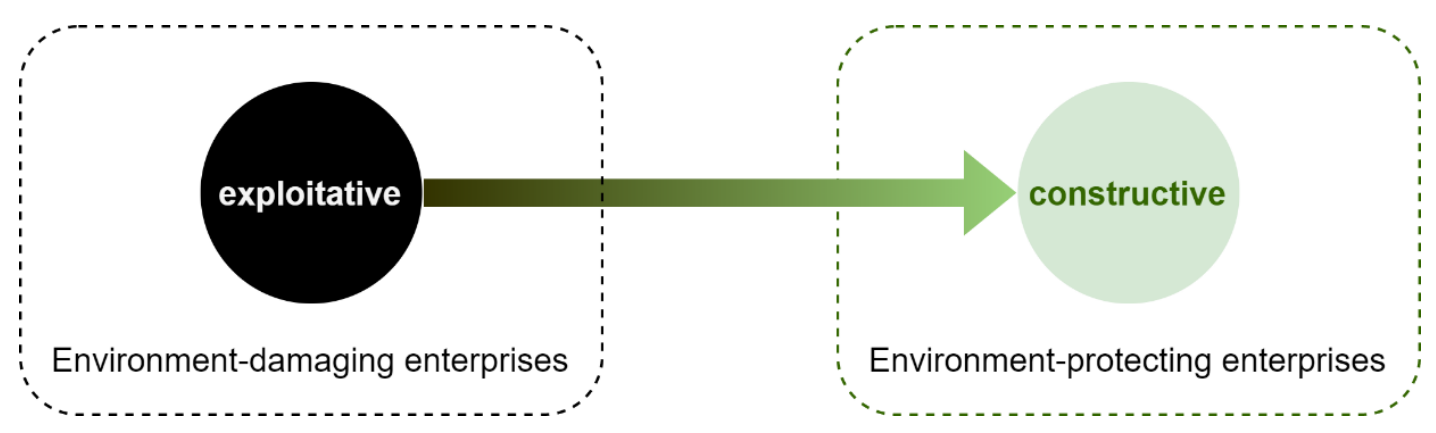

Figure 3. The transformation of core cultural value from "exploitative" to "constructive" 
This transformation takes place at the $\mathrm{Z}$ level, also known as the innermost core. In a rather binary simplification of the climate problem, we posit that there are two primary modes of core environmental cultural value: the "exploitative" and the "constructive." If the modus operandi is "exploitative," then the whole system from Y to W is built on this "exploitative" core value, thus, producing the so-called environment-damaging enterprises. By contrast, if "constructive" lies at the core value, the whole system would yield environment-protecting enterprises. Sustainability, after all, has to be built into the very default core cultural value.

\section{Synthesis}

In the past five decades, the world has witnessed that human beings maximize the exploitation of environmental resources for growth. Still, in the next five decades, there might be no choice but to protect the environment in order to survive and thrive. The current $4^{\text {th }}$ industrial revolution, known as Industry 4.0, is transforming manufacturing, services, and to a large extent, cultures, whether they be a culture of innovation, a culture of digitization, a culture of big data, or culture of smart and green technologies. It seems that the societal change from "monetarism" to "environmentalism" is an inevitable and irreversible trend. Supplementing the list of ten human cultures by Harrison and Huntington (2001), the authors suggest that the environmentally-friendly cultural value could be the $11^{\text {th }}$ human-culture.

To engage the business sector in the taskforce for protecting and healing nature, improving sustainability conditions, one should not ignore the corporate entity's raison d'être: maximizing its profitability as its "bottom-line" (Vuong, Ho, Nguyen, \& Nguyen, 2019). Fortunately, given the mindsponge modus operandi (Vuong, 2016; Vuong \& Napier, 2015), this very profitability notion can be constructed to include a cultural element that serves our purpose. That means it is time to build a new notion of profitability measured by the degree of helpfulness 
in healing nature and improving sustainability conditions. By this line of reasoning, the net profits will have the following form:

$$
N N P=N M P+N E V
$$

where, NNP is the new notion of New Net Profits, NMP the normal Net Monetary Profits, and NEV the new notion of Net Environmental Value.

An emerging environment-healing business system will need to reward both types of profits. And the system will need to exhibit one "semiconducting" feature: the environmental value can be accounted for as a monetary one, but NOT vice versa. The current carbon trading system, for instance, has thus far lacked this very "semiconducting" property.

To sum up, the new paradigm of environmentally-friendly cultural values proposed here embraces two mutually interacting attributes. First, money cannot trade for environmental deficits. Second, environmental embellishment value needs to become a new "measure of profit," priced at least on par with monetary value. The new environmentally-friendly cultural value-based approach addresses the carbon emission trade-related shortcomings and draws a new direction for adopting a new profit measure unit of enterprises. In other words, for example, when planning for a factory or a production project, unlike the old approach that considers how much of environmental loss one can bear, the new one considers how much of an environmental profit one can gain. Recognizing and agreeing to this new approach is difficult but vital. Realizing the environmental value will determine if Harrison's set of progressive values will be of value anymore. It is because humankind will face the biggest threat of extinction if the environment continues to be damaged to an irreparable level. 


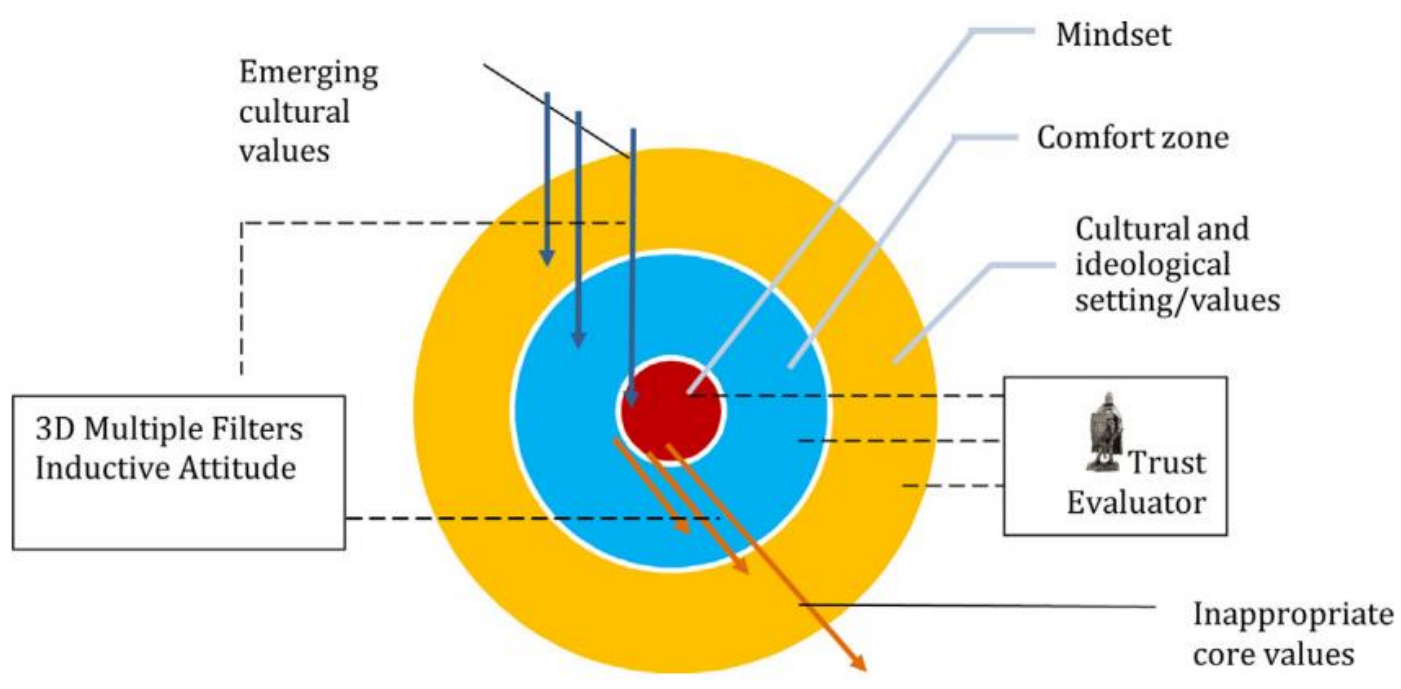

Figure 4. Mindsponge mechanism transforms mindset (Vuong \& Napier, 2015)

The transformation and transition toward the new paradigm of environmentally-friendly cultural values at the enterprise level is essentially a reset in mindset, which is attributable to a long process of adaption and adoption of new core values (Bernecker \& Job, 2019; Keller, Bieleke, \& Gollwitzer, 2019; Vuong \& Napier, 2015). As such, it would take time and require some conditions. First of all, gradually eliminating prejudice and developing an open-minded attitude are two important factors because these would enable humans to eventually step outside of their comfort zone or "core value" to learn and share the environmentally-friendly cultural values (Figure 4) (Vuong, 2016; Vuong \& Napier, 2015). This is followed by a gracious attitude, which is often missing in the negotiations among enterprises and or governments, policy-makers, etc. Just as Mother Teresa had said, "when we judge someone, we don't have time to love them," lacking a gracious attitude or approach will always be a barrier to feasible and comprehensive solutions to climate change. The climate crisis is a global problem that transcends all national boundaries and may span for centuries, so enterprises need a bigger vision of core interests and benefits. When setting bigger and more long-term goals, it is natural that small conflicts or 
obstacles would be easily seemingly overlooked. Prejudices would be faded gradually, which would create more opportunities for enterprises to adopt and adapt the new approach comfortably.

\section{Closing notes}

George Bernard Shaw, an Irish playwright, critic, polemicist, and political activist, once said, "Progress is impossible without change, and those who cannot change their minds cannot change anything." In this sense, understanding and acknowledging that global environmental change poses an increasing extinction risk to humanity is the first step of many important steps to come. This paper argues that enterprises and environmentally-friendly cultural values make up the pillars to address the climate crisis. Enterprises leave a large volume of carbon footprint, but they also have a great deal of potential to get to the heart of the problem and help to solve it. Simultaneously, as long as the cultural values and environmental values are well connected, there is always hope for effectively addressing the global problem. The transition and transformation toward the environment-healing cultural value in enterprises will take time and require several mutually interacting conditions such as a gracious and receptive attitude, no prejudice, big vision, and shared interests. In this regard, we propose some key solution directions to tackle the global environmental changes aforementioned.

First and foremost, it is essential to build "the environmental cultural values based-solution ecosystem" in which interdisciplinary solutions at multiple scales are integrated. Second, it is important to engage enterprises in policy design, social media, scientific research, and science communications, which would nurture the core environmentally-friendly cultural value. Third, in the digital age, it is paramount to have a strong database system (Mertens et al., 2019; Vuong et al., 2020), which would help monitor and assess more effectively to achieve the desirable program goals and objectives. Finally, upgrading enterprises' infrastructure system associated with 
advanced technologies should also be a priority for the long-term solutions to mitigate and adapt to environmental change challenges worldwide. Overall, the new paradigm presents valuable lessons for policy-makers in engaging enterprises in the fight for a more habitable and sustainable planet.

\section{References}

Adger, W. N., Barnett, J., Brown, K., Marshall, N., \& O’brien, K. (2013). Cultural dimensions of climate change impacts and adaptation. Nature Climate Change, 3(2), 112-117.

Bali Swain, R. (2017). A Critical Analysis of the Sustainable Development Goals (pp. 341-355).

Barnosky, A. D., Matzke, N., Tomiya, S., Wogan, G. O. U., Swartz, B., Quental, T. B., Marshall, C., McGuire, J. L., Lindsey, E. L., Maguire, K. C., Mersey, B., \& Ferrer, E. A. (2011). Has the Earth's sixth mass extinction already arrived? Nature, 471(7336), 51-57. doi:10.1038/nature09678

Bernecker, K., \& Job, V. (2019). Mindset Theory. In K. Sassenberg \& M. L. W. Vliek (Eds.), Social Psychology in Action: Evidence-Based Interventions from Theory to Practice (pp. 179-191). Cham: Springer International Publishing.

Boden, T. A., Marland, G., \& Andres, R. J. (2017). Global, Regional, and National Fossil-Fuel CO2 Emissions. Retrieved from Oak Ridge, Tenn., U.S.A. :

Clayton, S. (2020). Climate anxiety: Psychological responses to climate change. Journal of Anxiety Disorders, 74, 102263. doi:https://doi.org/10.1016/j.janxdis.2020.102263

Davies, P., Hernandez, M. P., \& Wyatt, T. (2019). Economy Versus Environment: How Corporate Actors Harm Both. Critical Criminology, 27(1), 85-99. doi:10.1007/s10612019-09433-z 
Ekwurzel, B., Boneham, J., Dalton, M. W., Heede, R., Mera, R. J., Allen, M. R., \& Frumhoff, P. C. (2017). The rise in global atmospheric CO2, surface temperature, and sea level from emissions traced to major carbon producers. Climatic Change, 144(4), 579-590. doi:10.1007/s10584-017-1978-0

Frumhoff, P. C., Heede, R., \& Oreskes, N. (2015). The climate responsibilities of industrial carbon producers. Climatic Change, 132(2), 157-171. doi:10.1007/s10584-015-1472-5

Galey, P. (2019). Climate impacts 'to cost world $\$ 7.9$ trillion' by 2050. Retrieved October 28, 2020 from https://phys.org/news/2019-11-climate-impacts-world-trillion.html

Griffin, P. (2017). CDP Carbon Majors Report 2017. Retrieved from https://b8f65cb373b1b7b15febc70d8ead6ced550b4d987d7c03fcdd1d.ssl.cf3.rackcdn.com/cms/reports/documents/000/0 02/327/original/Carbon-Majors-Report-2017.pdf

Harrison, L. E. (2000). Culture matters. The National Interest, 60, 55-65. Retrieved from https://nationalinterest.org/article/culture-matters-680

Harrison, L. E., \& Huntington, S. P. (2001). Culture Matters: How Values Shape Human Progress New York: Basic Books.

Heede, R. (2014). Tracing anthropogenic carbon dioxide and methane emissions to fossil fuel and cement producers, 1854-2010. Climatic Change, 122(1), 229-241. doi:10.1007/s10584-013-0986-y

Hickel, J. (2015). Five reasons to think twice about the UN's Sustainable Development Goals. Retrieved from https://blogs.lse.ac.uk/africaatlse/2015/09/23/five-reasons-to-think-twiceabout-the-uns-sustainable-development-goals/ 
IDI. (2020). Cambodia: Hoang Anh Gia Lai Rubber Plantations. Retrieved October 29, 2020 from https://www.inclusivedevelopment.net/campaign/cambodia-rubber-land-grabs/

IKEA. (2020). What does being climate positive mean for IKEA? Retrieved October 29, 2020, from https://about.ikea.com/en/sustainability/becoming-climate-positive/what-is-climatepositive

Johnson, C. N., Balmford, A., Brook, B. W., Buettel, J. C., Galetti, M., Guangchun, L., \& Wilmshurst, J. M. (2017). Biodiversity losses and conservation responses in the Anthropocene. Science, 356(6335), 270-275. doi:10.1126/science.aam9317

Keller, L., Bieleke, M., \& Gollwitzer, P. M. (2019). Mindset Theory of Action Phases and IfThen Planning. In K. Sassenberg \& M. L. W. Vliek (Eds.), Social Psychology in Action: Evidence-Based Interventions from Theory to Practice (pp. 23-37). Cham: Springer International Publishing.

Kulp, S. A., \& Strauss, B. H. (2019). New elevation data triple estimates of global vulnerability to sea-level rise and coastal flooding. Nature Communications, 10(1), 4844. doi:10.1038/s41467-019-12808-z

Kuo, T. C., Hong, I. H., \& Lin, S. C. (2016). Do carbon taxes work? Analysis of government policies and enterprise strategies in equilibrium. Journal of Cleaner Production, 139, 337-346. doi:https://doi.org/10.1016/j.jclepro.2016.07.164

Lapan, H. E., \& Sikdar, S. (2019). Is Trade in Permits Good for the Environment? Environmental and Resource Economics, 72(2), 501-510. doi:10.1007/s10640-017-0202- 
McMahon, J. (2018). How Tesla Scored A Zero On Climate Management. Retrieved October 29, 2020, from https://www.forbes.com/sites/jeffmcmahon/2018/06/27/how-tesla-earneda-zero-score-for-climate-management/

Mertens, E., Kaptijn, G., Kuijsten, A., van Zanten, H., Geleijnse, J. M., \& van 't Veer, P. (2019). SHARP-Indicators Database towards a public database for environmental sustainability. Data in Brief, 27, 104617. doi:https://doi.org/10.1016/j.dib.2019.104617

Mor, S., Toma, C., Schweinsberg, M., \& Ames, D. (2019). Pathways to intercultural accuracy: Social projection processes and core cultural values. European Journal of Social Psychology, 49(1), 47-62.

Nunn, R., O’Donnell, J., Shambaugh, J., Goulder, L. H., Kolstad, C. D., \& Long, X. (2019). Ten facts about the economics of climate change and climate policy: A joint report from The Hamilton Project and the Stanford Institute for Economic Policy Research. Retrieved from https://www.brookings.edu/research/ten-facts-about-the-economics-of-climatechange-and-climate-policy/

Peter, Z., \& Pheap, A. (2014). Rubber Firm Accused of Illegal Logging Puts Work on Hold. Retrieved October 29, 2020, from https://english.cambodiadaily.com/news/rubber-firmaccused-of-illegal-logging-puts-work-on-hold-58287/

Plagányi, É. (2019). Climate change impacts on fisheries. Science, 363(6430), 930-931. doi:10.1126/science.aaw5824

Price, L., Sinton, J., Worrell, E., Phylipsen, D., Xiulian, H., \& Ji, L. (2002). Energy use and carbon dioxide emissions from steel production in China. Energy, 27(5), 429-446. doi:https://doi.org/10.1016/S0360-5442(01)00095-0 
Ray, D. K., West, P. C., Clark, M., Gerber, J. S., Prishchepov, A. V., \& Chatterjee, S. (2019). Climate change has likely already affected global food production. PLOS ONE, 14(5), e0217148. doi:10.1371/journal.pone.0217148

Reuters. (2020). IKEA reduces climate footprint for the first time. Retrieved October 29, 2020, from https://www.reuters.com/article/us-ikea-emissions/ikea-reduces-climate-footprintfor-the-first-time-idUSKCN20LOVI

Rimmer, M. (2018). Elon Musk's Open Innovation: Tesla, Intellectual Property, and Climate Change. In M. Rimmer (Ed.), Intellectual Property and Clean Energy: The Paris Agreement and Climate Justice (pp. 515-551). Singapore: Springer Singapore.

Rosen, A. M. (2015). The Wrong Solution at the Right Time: The Failure of the Kyoto Protocol on Climate Change. Politics \& Policy, 43(1), 30-58. doi:10.1111/polp.12105

Rosenbloom, D., Markard, J., Geels, F. W., \& Fuenfschilling, L. (2020). Opinion: Why carbon pricing is not sufficient to mitigate climate change — and how "sustainability transition policy" can help. Proceedings of the National Academy of Sciences, 117(16), 8664-8668. doi:10.1073/pnas.2004093117

Seidl, R., Thom, D., Kautz, M., Martin-Benito, D., Peltoniemi, M., Vacchiano, G., Wild, J., Ascoli, D., Petr, M., Honkaniemi, J., Lexer, M. J., Trotsiuk, V., Mairota, P., Svoboda, M., Fabrika, M., Nagel, T. A., \& Reyer, C. P. O. (2017). Forest disturbances under climate change. Nature Climate Change, 7(6), 395-402. doi:10.1038/nclimate3303

Shah, H. (2020). Global problems need social science. Nature, 577(7790), 295-295.

Straughan, E., \& Dixon, D. (2012). Cultural response to climate change. Nature Climate Change, 2(7), 480-481. 
United Nations. (1992). United Nations Framework Convention on Climate Change. Retrieved from https://unfccc.int/resource/docs/convkp/conveng.pdf

United Nations. (2015). Resolution adopted by the General Assembly on 25 September 2015, Transforming our world: the 2030 Agenda for Sustainable Development.

van den Bergh, J., \& Botzen, W. (2020). Low-carbon transition is improbable without carbon pricing. Proceedings of the National Academy of Sciences, 117(38), 23219-23220. doi:10.1073/pnas.2010380117

Victor, D. (2015). Climate change: Embed the social sciences in climate policy. Nature, 520(7545), 27-29.

Vuong, Q.-H. (2020). The semiconducting principle of monetary and environmental values exchange. Retrieved from https://osf.io/nv3yz

Vuong, Q.-H., Ho, M.-T., Nguyen, H.-K. T., \& Nguyen, M.-H. (2019). The trilemma of sustainable industrial growth: evidence from a piloting OECD’s Green city. Palgrave Communications, 5(1), 156. doi:10.1057/s41599-019-0369-8

Vuong, Q.-H., La, V.-P., Nguyen, H.-K. T., Ho, M.-T., Vuong, T.-T., \& Ho, M.-T. (2020). Identifying the moral-practical gaps in corporate social responsibility missions of Vietnamese firms: An event-based analysis of sustainability feasibility. Corporate Social Responsibility and Environmental Management 27(6): in press. doi:10.1002/csr.2029

Vuong, Q. H. (2016). Global mindset as the integration of emerging socio-cultural values through mindsponge processes: A transition economy perspective Global Mindsets (pp. 123-140): Routledge. 
Vuong, Q. H., \& Napier, N. K. (2015). Acculturation and global mindsponge: An emerging market perspective. International Journal of Intercultural Relations, 49, 354-367. doi:10.1016/j.ijintrel.2015.06.003

Waas, M. (2014). Culture and the Environment: How Cultural Values Influence Global Ecologic Practices. Retrieved October 29, 2020, from https://chicagopolicyreview.org/2014/12/04/culture-and-the-environment-how-culturalvalues-influence-global-ecologic-practices/

White House. (2017). Statement by President Trump on the Paris Climate Accord [Press release]. Retrieved from https://www.whitehouse.gov/briefings-statements/statement-presidenttrump-paris-climate-accord/

Yanjia, W., \& Chandler, W. (2010). The Chinese nonferrous metals industry-energy use and CO2 emissions. Energy Policy, 38(11), 6475-6484.

doi:https://doi.org/10.1016/j.enpol.2009.03.054

Zhang, Y., Yuan, Z., Margni, M., Bulle, C., Hua, H., Jiang, S., \& Liu, X. (2019). Intensive carbon dioxide emission of coal chemical industry in China. Applied Energy, 236, 540550. doi:https://doi.org/10.1016/j.apenergy.2018.12.022 